\title{
Advanced Modularity Design for The MIT Pebble Bed Reactor
}

\author{
Andrew C. Kadak \\ Department of Nuclear Engineering \\ Massachusetts Institute of Technology \\ Marc V. Berte \\ Graduate Student \\ Department of Nuclear Engineering \\ Massachusetts Institute of Technology
}

\section{2nd International Topical Meeting on High Temperature Reactor Technology}

\author{
Institute of Nuclear and New Energy Technology \\ Friendship Hotel, Haidian District \\ Beijing, China
}

September 22-24, 2004

\begin{abstract}
The future of all reactors will depend on whether they can be economically built and operated. One of the major impediments to new nuclear construction is the capital costs due in large part to the length of construction time and complexity of the plant. Pebble bed reactors offer the opportunity to reduce the complexity of the plant because the number of safety systems required is significantly reduced due to the inherent safety of the technology, However, because of its small size the capital cost per kilowatt is likely to be large if traditional construction approaches are followed. This strongly suggests innovative construction concepts to reduce the construction time and cost. MIT has proposed a modularity approach in which the plant is pre-built in spaceframe type modules which are built in factories. These space frames would contain all the equipment contained in a given volume. Once equipment in the space frame is installed, the space frame would then be shipped to the site and assembled "lego-style." Studies presently underway have demonstrated the feasibility of the concept. Thermal stress analysis has been performed and an integrated design with the space frames has been developed. It is expected that this modularity approach will significantly shorten construction time and expense. This paper will summarize the results to-date.
\end{abstract}




\section{Advanced Modularity Design for The MIT Pebble Bed Reactor}

\section{Introduction}

The capital cost of new nuclear plants is the most significant reason for the lack of interest by the electric generation industry. Despite the fact that nuclear energy provides an opportunity to demonstrably reduce global carbon emissions, the cost of building new plants is a significant barrier to their construction. For nuclear energy to emerge as the energy source of choice, not only must the environmental benefits be accepted but the cost must be competitive with alternative sources of energy. At present, the environmental benefit is not sufficiently recognized nor are the present nuclear plants on the market judged to be economically competitive.

The new nuclear plants on the market today are large light water reactors of the so-called "Generation III" vintage. Generation III reactors are evolutionary light water reactors already certified by the Nuclear Regulatory Commission which need only to be ordered to be built since the safety reviews have been completed in the certification process. These reactors still largely depend on emergency core cooling systems that are necessary to prevent core meltdowns. Such complexity costs money, raises generating cost and construction time.

To deal with these extra costs, vendors have decided that the best way to deal with reducing the cost of power is to make the generating stations larger taking advantage of economies of scale by producing more power in only a slightly larger footprint. While these economies do work, the larger the plant, the higher the cost and the longer it will take to build. The expectation is that with the larger power output, the cost of power will be lower in the end.

This traditional thinking is being challenged by the MIT pebble bed project. Rather than relying on the economies of scale to reduce costs, the economies of mass production will be used. By building smaller plants with factory built and site assembled modules, the cost and time for construction can be greatly reduced. The modular approach being developed by the MIT design team is also different than what others have called "modular" reactors. The MIT definition of modular making modules that are either truck or train shippable that can be assembled at the site. Modular does not mean taking a 1200 Mwe plant and making into four 300 Mwe "module" plants. The design constraint for the MIT Modular Pebble Bed Reactor (MPBR) is what can be shipped by truck or train. This will limit the size of the components and ultimately the reactor. The target size of the MPBR is approximately $250 \mathrm{Mwth}$ based on this criteria. This paper will describe the modularity concept proposed that will hopefully yield a commercially attractive approach for further development.

\section{Background}

The MIT Pebble Bed project is developing a conceptual design of a 250 Mwth - 120 Mwe Modular Pebble Bed Reactor (MPBR) using an indirect helium to helium heat exchanger gas turbine cycle power plant [1]. The basic design parameters are shown on Table 1. 


\begin{tabular}{|l|l|}
\hline Thermal Power & $250 \mathrm{MW}$ \\
\hline Gross Electrical Power & $132.5 \mathrm{MW}$ \\
\hline Net Electrical Power & $120.3 \mathrm{MW}$ \\
\hline Plant Net Efficiency & $\begin{array}{l}48.1 \% \text { (Not take into account cooling IHX } \\
\text { and HPT. if considering, it is believed }> \\
45 \%)\end{array}$ \\
\hline Helium Massflowrate & $126.7 \mathrm{~kg} / \mathrm{s}$ \\
\hline Core Outlet/lnlet T & $900^{\circ} \mathrm{C} / 520^{\circ} \mathrm{C}$ \\
\hline Cycle pressure ratio & 2.96 \\
\hline Power conversion unit & Three-shaft Arrangement \\
\hline
\end{tabular}

Table 1: Basic Plant Parameters for the MIT Pebble Bed Reactor [2]

A schematic of the plant operating parameters and conditions [2] is shown on Figure 1. The present design utilizes existing technology that has been demonstrated. The resulting three shaft system is limited to a nominal demonstrated shaft horsepower. The overall power conversion system is a three shaft - one low speed power shaft driving a generator and two separate turbocompressor sets The basis of this selection was to limit the shaft power of any one turbine to less than $\sim 36 \mathrm{MW}$ (to stay within existing turbomachinery designs). Additionally, by reducing the length of each individual turbocompressor set, it becomes easier to layout the reactor plant as each shorter shaft can be positioned in adjacent modules, horizontally or vertically.

Second, the intermediate heat exchanger (IHX) consists of six smaller modules each with its own containment vessel. This was done to limit the weight of each module to within the $200 \mathrm{k} \mathrm{lb}$ truck limit. Additionally, by splitting the IHX up into smaller modules, if there is damage or failure to a part of the IHX, the smaller module can be removed and replaced. As the IHX will in all probability be contaminated by fission products or fuel pebble debris, the six module arrangement minimizes the cost of an IHX repair since the most likely damage would be confined to a single module.

The recuperator is split up into six modules similar to the IHX. This enables each recuperator module to be closely located to a corresponding IHX module, limiting the amount of piping required between the two. The separate recuperator modules also permit easy maintenance and ease of replacement, like the IHX modules.

The balance of plant layout shown in Figure 2 is proposed. This layout seeks to maximize the modularity of the design by concentrating manifolds and plumbing in individual modules, while restricting the each module to a single type of component (keeping turbomachinery in separate modules from heat exchangers whenever possible to minimize parasitic effects during maintenance). 


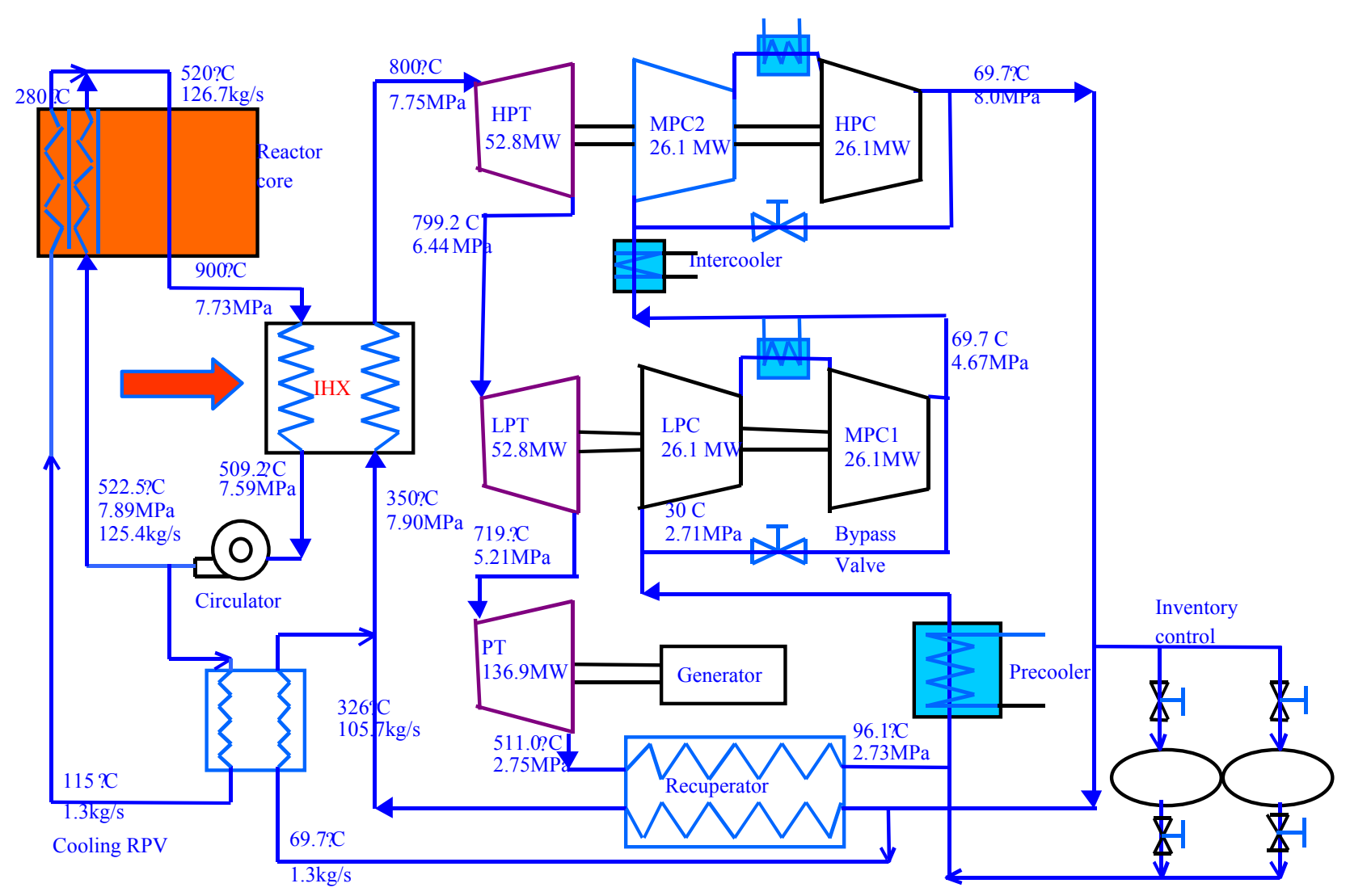

Figure 1: Current Plant Schematic

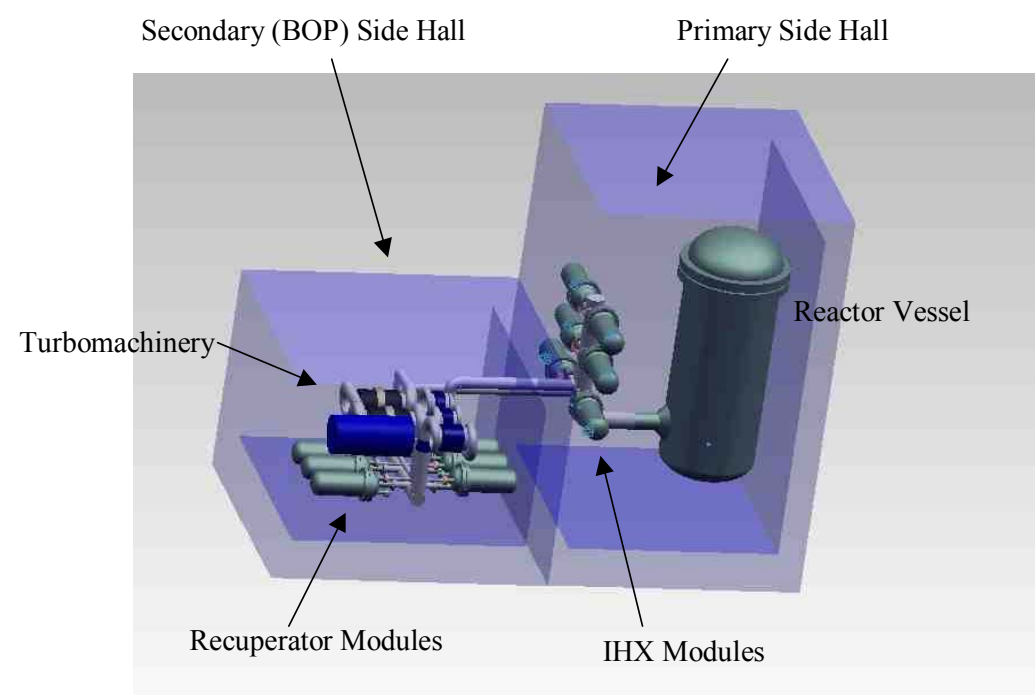

Figure 2: Preliminary Conceptual Layout of the MIT PBR 


\section{Modularity Principles in Design [3]}

The initial concept for the MPBR was to build all the parts in a central factory and ship them to the construction site, where they would be assembled in a simple, bolt together, plug and play fashion, loaded with fuel and powered up [4].

The MPBR project is highly dependent on the ability to package the reactor, its intermediate heat exchanger (IHX), and the remaining balance of plant in such a way to allow the MPBR plant to be transported via low cost means (truck as opposed to barge), easily assembled with minimal tooling and re-working, and operated in a small footprint commensurate with conventional power plants. Based on this dependency, the following requirements and assumptions can be made.

All components other than the reactor vessel and its associated mechanical support systems must be transportable by heavy lift tractor/trailer truck. Given that heavy lift trucks are used to transport the BOP components to the plant location, the following limitations must be met. First, the maximum dimensions of any one module are 8' wide, 12' tall, and up to 60' long. Second, the maximum weight of a single module must be less than $\sim 200,000 \mathrm{lb}$. Finally, the modules must be contained in a steel space frame to support the components within and to align those components with the components in other modules. The assembly on site of the modules must be limited to stacking the space-frames to align the various flanges and bolting the piping together.

The modularity and packaging studies performed for the MPBR project can be broken down into three tasks: 1. System layout and design (physical layout and packaging of the plant components), 2. System concept design for increased modularity and decreased cost, and 3. Advanced component design concepts for future implementation. The first task involves defining the physical layout of the power plant itself, and the breakdown of any transportation issues involved in its construction. The second task involves making high level trade studies of the actual system, such as the number of intercoolers, limiting temperatures, and other system parameters. The third task involves searching for advanced component concepts that may aid in the other two tasks by making individual components simpler, cheaper, or more fault tolerant.

The primary concept that defines the innovation of this proposed MPBR modularity approach is the minimization, and where possible, elimination, of the new capital facilities, on-site construction, and labor required to construct a nuclear power plant. This approach is defined by a new way to examine how components are built and assembled. In the past nuclear power plant construction has been performed almost completely on site, as most of the components are far to large to transport assembled. Each new plant was effectively a "new" plant, in that it shared little, even in "factory" plants, with its brethren. These plants also were putting a utilities eggs in one basket, as any major component failure would eliminate all $1000 \mathrm{MW}+$ of generating capacity until the part could be replaced, and given the complexity and assembly techniques used, such a repair could take a substantial amount of time, and require parts that weren't off-the-shelf available.

The MPBR will be built in a "virtual" factory in which individual component manufacturers would be asked to provide all components, piping connections, electric power connections and electronics for the volume occupied by the component in a space designated by a "space frame" (Figure 3). These space frames would then be assembled at the plant site using a simple, bolt 
together, plug and play style assembly process. This should dramatically reduce construction time and costly field work.

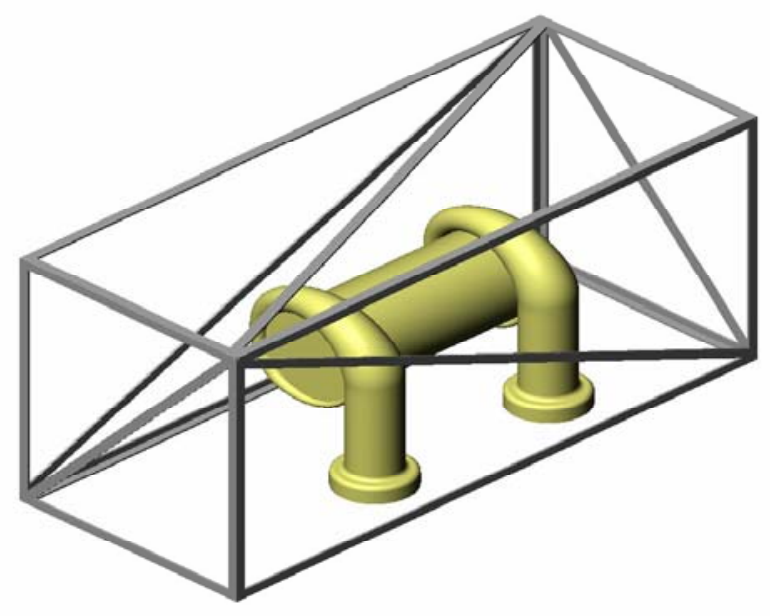

Figure 3: Space Frame Example

\section{System Layout and Design}

The resulting plant layout can be graphically visualized as shown in Figure 4 which is a view from the top of the plant looking down. The dotted lines that are shown indicate the shippable space frame modules for this design. The modules are arranged on two levels which are not shown. This layout is designed to minimize the number of modules that need to be removed to access any one module. To ensure this, the only modules whose replacement would necessitate the removal from the plant of a functioning module is the lower level manifold module, all other modules can be extracted either from above for the top level modules, or from the side (on sliding rails) for all the lower level modules.

This layout also simplifies construction of the plant, as the only large machinery needed to emplace the modules is a crane to emplace the top-level modules. Given the low lift height and overhead clearance needed to emplace these modules, such a crane could be limited to a hydraulic lift carriage, deliverable by truck, that would grasp each module, lift it to the correct height, and slide it onto rails built into the lower modules. Using this type of assembly, the amount of site preparation for the BOP part of the facility is minimal (a suitable pad type foundation with the 
proper load bearing specifications) and the on site tooling and machinery requirements is minimal (lift carriage, stud tensioner and flange assembly tools).

Overall, this layout requires the use of 21 modules (not including command and control or power processing), each of which is truck transportable (Figure 5).

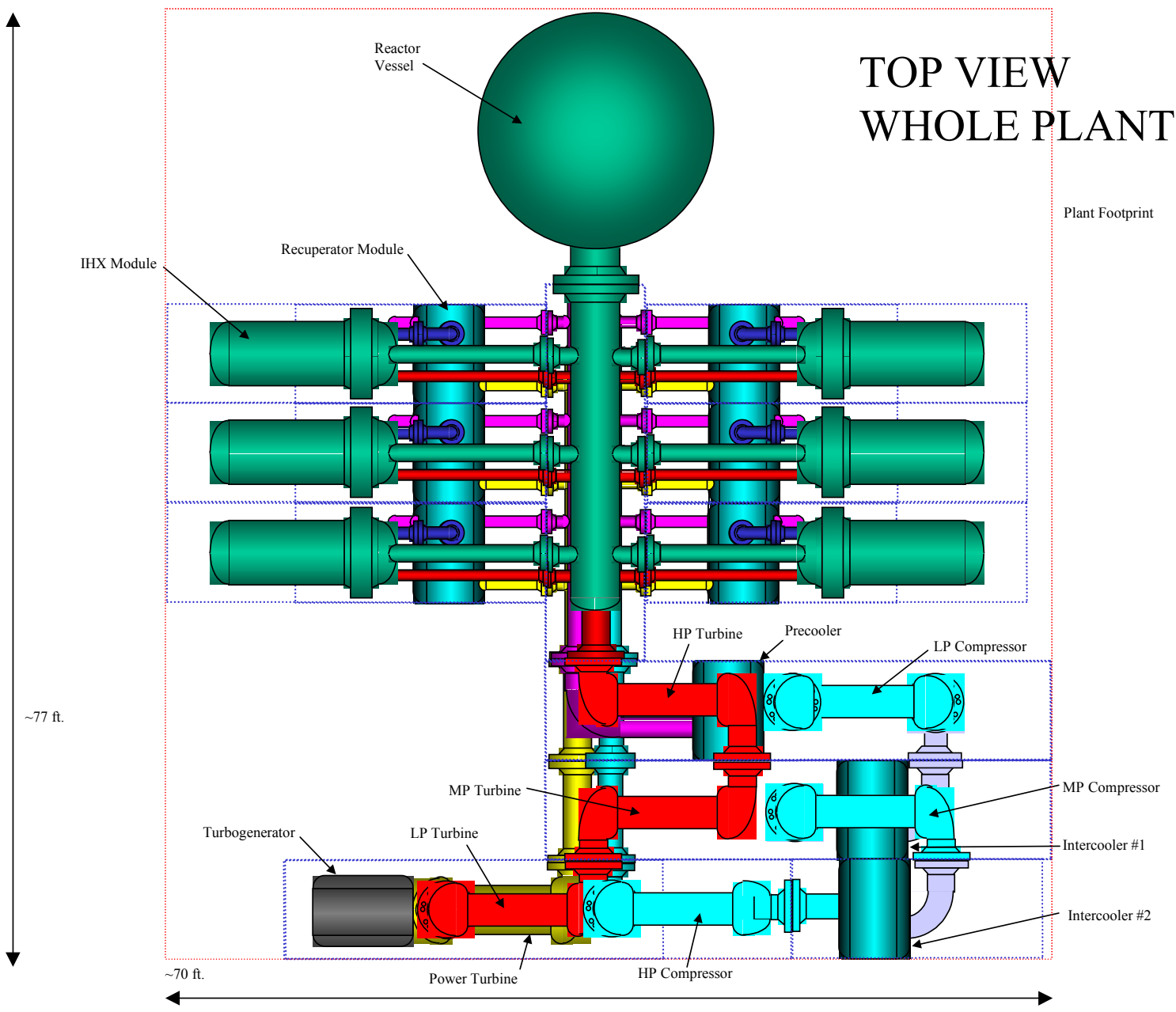

Figure 4: Top Down View of Pebble Bed Reactor Plant 


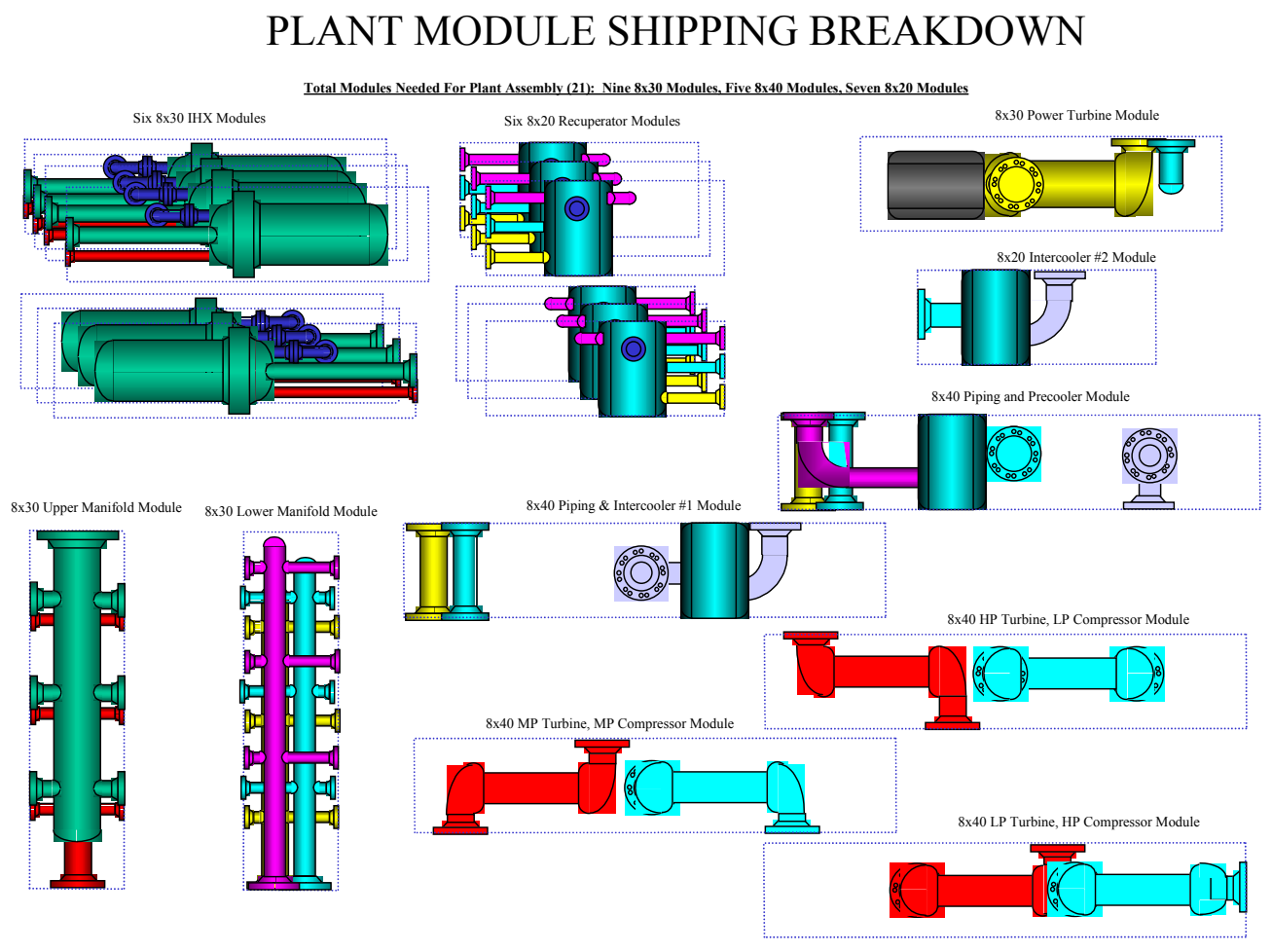

Figure 5: Shipping Modules for Balance of Plant

While this type-specific module isolation increases the total number of modules in the system, it limits the amount of functioning components that have to be removed during replacement of a single component. This is necessary, as the current strategy for repair of this type of reactor facility is one of replacement rather than on-site repair. Each module will be built in a centralized factory, and is transportable by truck. Therefore, when a component fails on site, that specific module will be removed and returned to the factory for repair, with an identical replacement module taking its place. This layout also maximizes the effectiveness of this strategy as each of the IHX and recuperator modules are identical, thus, a single spare IHX or recuperator module can be used to replace any one of the six original modules.

While not shown on this layout design, plant command and control facilities and electrical metering / distribution modules would be shipped in similar containers and also assembled on site in a similar fashion. The addition of these modules is what drove the location of the generator / power turbine module to its present location at the lower left of the layout, as additional power processing modules could be added adjacent to it without compromising the removal path of any other modules. Command and control modules could be added in two levels across from these modules (adjacent to the turbocompressor / intercooler modules).

The largest single component is the reactor vessel which has been preliminarily reviewed for modularity. While shipment as a single vessel is possible by barge, to maintain the modularity 
approach described necessitates segmenting the vessel into 5 ring segments. The determination of whether the vessel would be flanges (requiring massive flange sections) or simply field welded would be made in future studies. Juelich has proposed and tested a cast iron segmented pretensioned vessel as a solution that will also be considered.

The balance of plant fits in a footprint roughly $80 \mathrm{ft} \times 70 \mathrm{ft}$, a comparable size to $100 \mathrm{MWe}$ gas turbine facilities, and far smaller than conventional nuclear plants. With reactor vessel, such a plant could easily be made to fit within a $125 \mathrm{x} 80 \mathrm{ft}$ footprint, for a power density of roughly $10 \mathrm{~kW} / \mathrm{ft}^{\wedge} 2$. For a conventional $1 \mathrm{Gwe}$ plant, this power density would require a facility footprint of $\sim 100,000 \mathrm{ft}^{\wedge} 2$ Given that conventional reactor containment buildings (not including the turbine shed and control facilities) consume nearly 40,000 sqft on their own, this power density is equal to, if not greater than conventional facilities, including advanced gas turbine systems.

\section{Manufacturing and Assembly Sequence}

This manufacturing and assembly sequence would work as follows.

A series of subcontractors would be selected for all the various components based on expertise, cost or the existence of a stock part - for example, Pratt \& Whitney, General Electric, could be selected to manufacture the turbomachinery (expertise and existing production capability), and Siemens could be selected for the circulator and inventory control motors (existence of a stock part).

Second, as each of the major subcontractors should have the capability of constructing a standard, low-tech space-frame, each module subcontractor would integrate their component into the standard frame along with all of the support equipment which would be designed with a limited number of inter-module interfaces.

Third, for those subcontractors without the capability of constructing the standard frame, or those that simply do not wish to do so, any local fabrication shop could be used to construct the frame and deliver it via conventional truck to the subcontractor.

Fourth, site preparation entailing excavation and concrete construction creating the "rooms" for space frames is simple and could be performed by a chosen local contractor.

Fifth, a the transportation subcontractor would transport the finished modules (most designed to be either road or rail transportable) to the site where they would be assembled using minimum tools and equipment. Since the transportation subcontractor will move the same parts from the same locations to different destinations, a substantial learning curve can be developed as better routes can be mapped, escorts arranged in advance, etc.

Sixth, when the space frames arrive at the site, they will be emplaced in pre-configured locations. The connections of piping, electrical and instrumentation lines would then be made. The present design calls for bolted flanges for the piping and plug type connectors for the electrical and instrumentation systems. Should it be necessary to assure minimal helium leakage at the flanges, small weld beads to be used at the flanges similar to that currently done for submarines. This "lego" style assembly is illustrated by Figure 6 which is only used to capture the visualization of the concept. 
Once the plant is in operation, if a space frame (component) needs replacement, it should be readily available, as the subcontractors will be producing the parts continuously, and the next one produced will simply be trucked to an "old" destination - at low cost since the route has been done many times before.

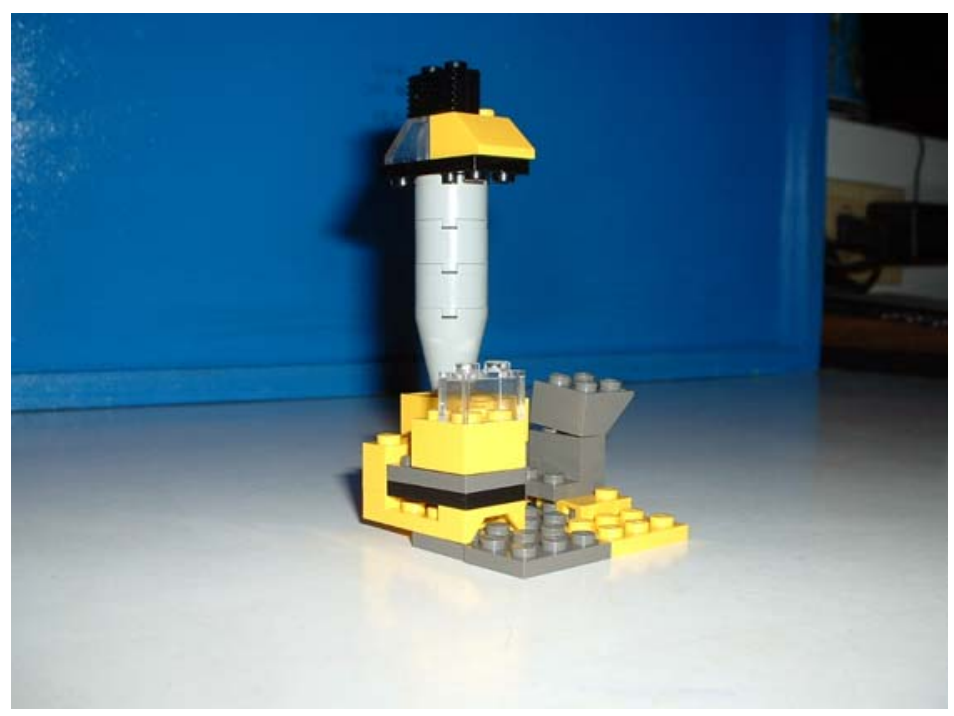

Figure 6: Visualization of Space Frame "Lego" Concept

This process exemplifies all of the lean manufacturing lessons being pursued currently, as it minimizes inventory, maximizes commonality of interface (common space frame, etc), enables the complex component subcontracts to be awarded to large, fixed-location established companies, while using lower cost local resources for the simple components and tasks. Observing advanced modular nuclear submarine construction at Newport News Shipyard and General Dynamics Shipyard at Quonset Point, Rhode Island, provides additional confidence that the concepts being proposed are quite practical and have demonstrated substantial cost savings in the fabrication of nuclear submarines.

\section{Construction Build-Out Plan}

The construction plan of the MPBR reactor system follows a step by step process described below, and illustrated in schematic form.

\section{Excavation}

The first step in the construction of the MPBR module is the excavation of the area for the containment / BOP building. There are two possibilities for the vertical layout of the MPBR plant. First, if it is necessary for the containment structure to be buried to the level of the top of the reactor vessel for accident heat transfer concerns, the excavation will go to a depth of $\sim 19 \mathrm{~m}$, 
at this depth, approximately $9 \mathrm{~m}$ of the primary side containment building will protrude above ground level.

\section{Foundation / Walls}

The MPBR containment building is separated into two volumes, the primary side (containing the reactor, IHX modules, and fuel handling apparatus) and the secondary side (containing the remainder of the BOP). Each of these volumes is enclosed with $1 \mathrm{~m}$ thick reinforced concrete walls, and a $2 \mathrm{~m}$ thick floor. This will provide the necessary protection of the MPBR system from outside projectiles, and contain any pressure buildups caused by catastrophic leaks. The primary side internal dimensions are approximately $15 \times 15 \times 25 \mathrm{~m}$ while the secondary side dimensions are $15 \times 15 \times 10 \mathrm{~m}$ (for the above ground layout). For a fully submerged layout, the two volumes would have the same height). Given this internal volume, if the entire helium inventory were vented into the building, the internal pressure would only increase by approximately $100 \mathrm{kPa}$ (assuming zero cooling, once cooled, the pressure would only be $\sim 25 \mathrm{kPa}$ above ambient). Not shown in the building layout is the extension of the two volumes laterally at ground level by approximately $5 \mathrm{~m}$. This "shelf" is the loading area where modules are positioned on a hydraulic dolly to be moved outside of the containment structure (through a sliding, sealed, concrete door) for transportation.

\section{Vertical module supports (IHX, manifolds)}

In order to facilitate replacement of the IHX modules, a steel beam structure is erected in the primary side volume that supports the both the IHX modules and the manifold modules during normal operation. This structure extends in a stepped fashion toward the reactor vessel to provide rails to slide the IHX modules out for replacement. An additional steel beam structure encircles the top of the reactor module to support the fuel handling modules. The reactor vessel itself is supported by a steel and concrete ring extending upward from the floor of the primary volume. These support structures, along with a shelf-like loading dock structure, are not shown in the illustrations for clarity purposes.

\section{Bridge Crane Installation / Requirements}

The bridge cranes used to install and replace the various modules are required to emplace and remove the modules in each volume. The IHX modules are the heaviest modules in the primary volume, with a mass of $\sim 40,000 \mathrm{~kg}$ (except the reactor vessel). A loaded spent fuel module will have a similar mass. On the secondary side, the heaviest module is the turbo-generator module which weighs approximately $300,000 \mathrm{~kg}$. However, the design for a suitable bridge crane to accommodate the generator module, the bridge crane can be sized for the next heaviest component, the turbo-compressor sets, which weigh approximately 45,000kg. The turbogenerator module, given its position at the edge of the layout, with no modules placed underneath it, enables it to be removed and lifted to surface level using a short span gantry / bridge crane. This crane will be able to lift the generator module vertically and move laterally to remove the generator module from the building.

\section{Latest Design Concept}

One of the key issues in high temperature gas reactors is the ability to manage the high temperatures and resulting system expansion. The space frame concept must be able to 
accommodate such movement without inducing large thermal stresses. To that end and thermal stress analysis has been performed which necessitated revisions to the basic layout. The space frames will be used to support the components and piping within the frame and allow flexible movement of the components. This design has yielded the layout as shown in Figure 7.

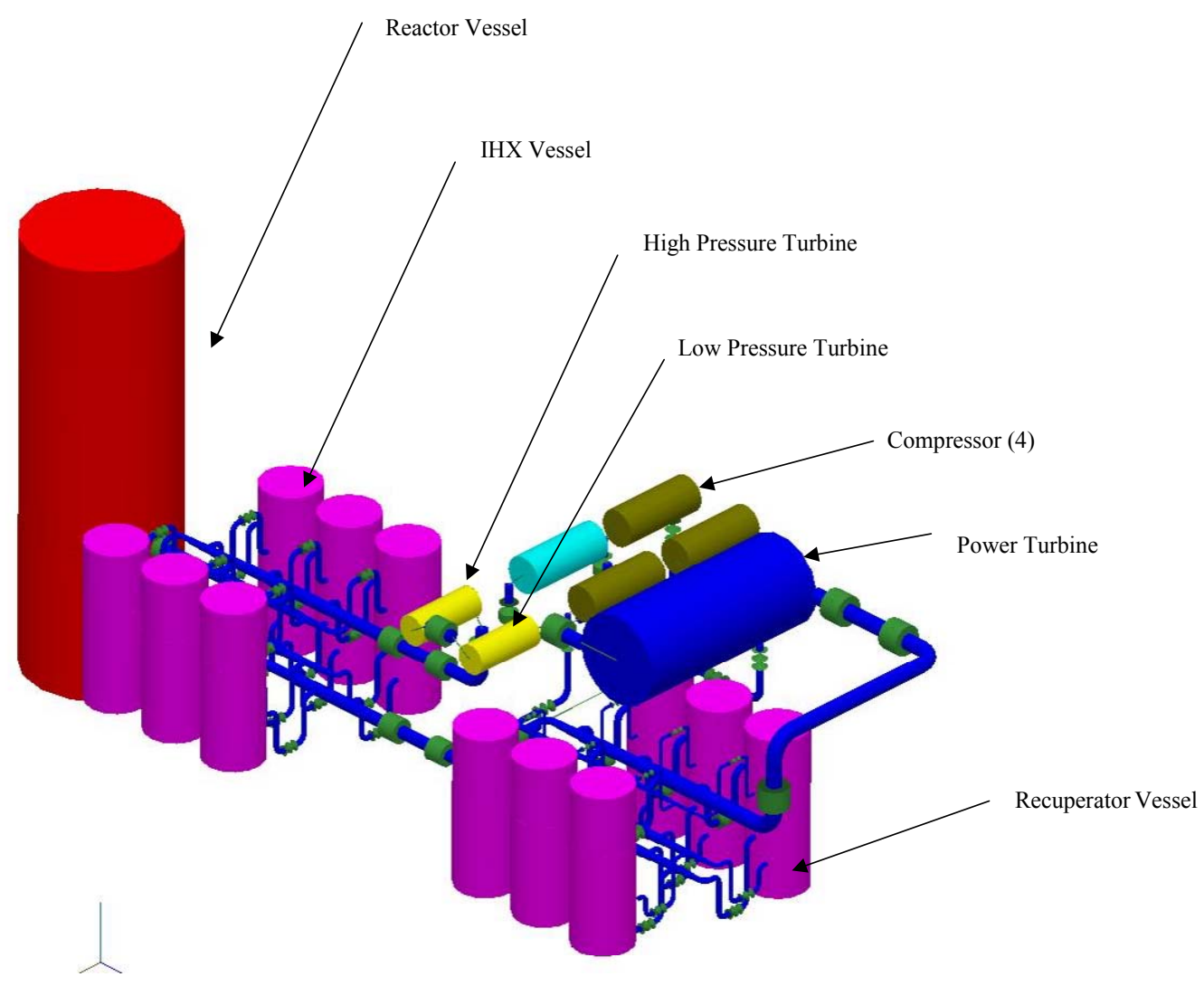

Figure 7: Latest Design Layout to Accommodate Thermal Expansion

One of the most difficult alignment challenges is that associated with common headers and connecting piping in the space frames as shown in Figure 8 


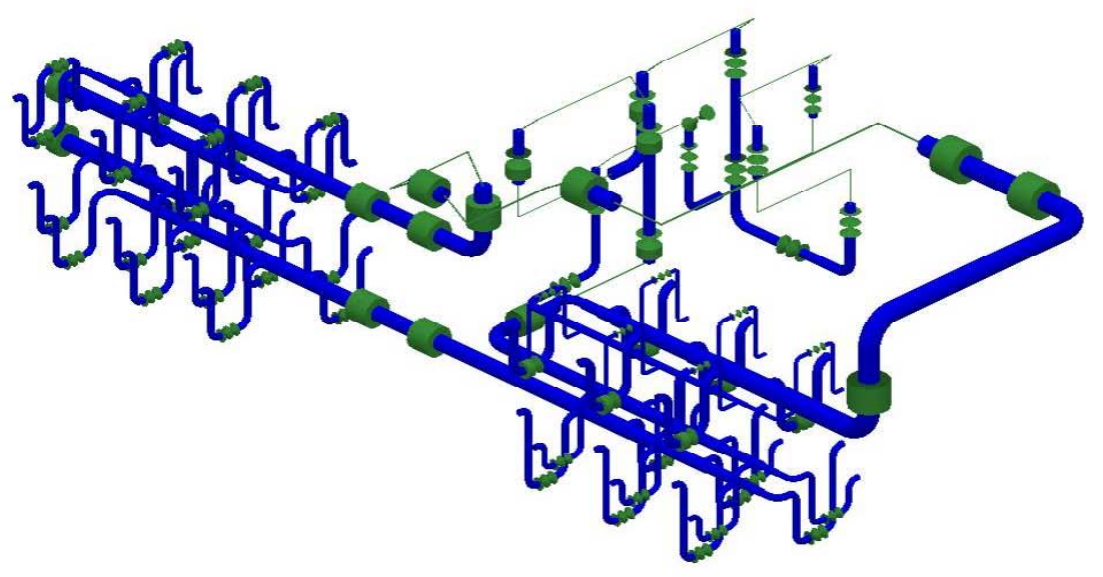

Figure 8: Details of Connecting Piping

When this plant is segregated in to plant modules, the resultant plant configuration is shown in Figure 9. The process of design and build incorporates significant engineering input to allow for efficient modular construction. Three dimensional models of the ship's design and construction plan are developed to allow for system installation on a critical path schedule to assure that all parts can be fit into the modules at the proper time. 


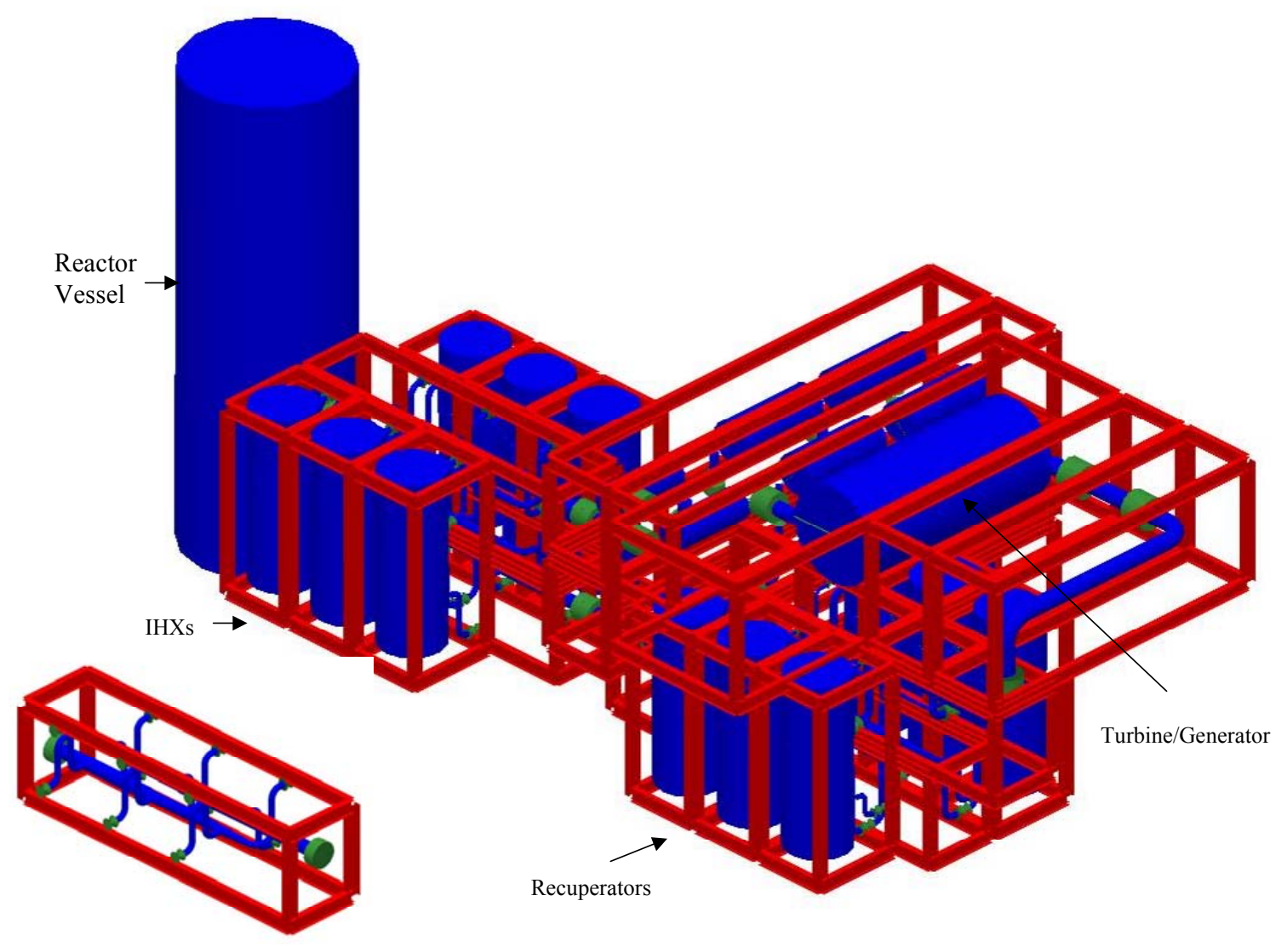

Figure 9: Current MIT Pebble Bed Reactor Showing Space Frame Configuration 
Shown on Figure 10 is how this reactor system fits into the plant structures as previously explained.

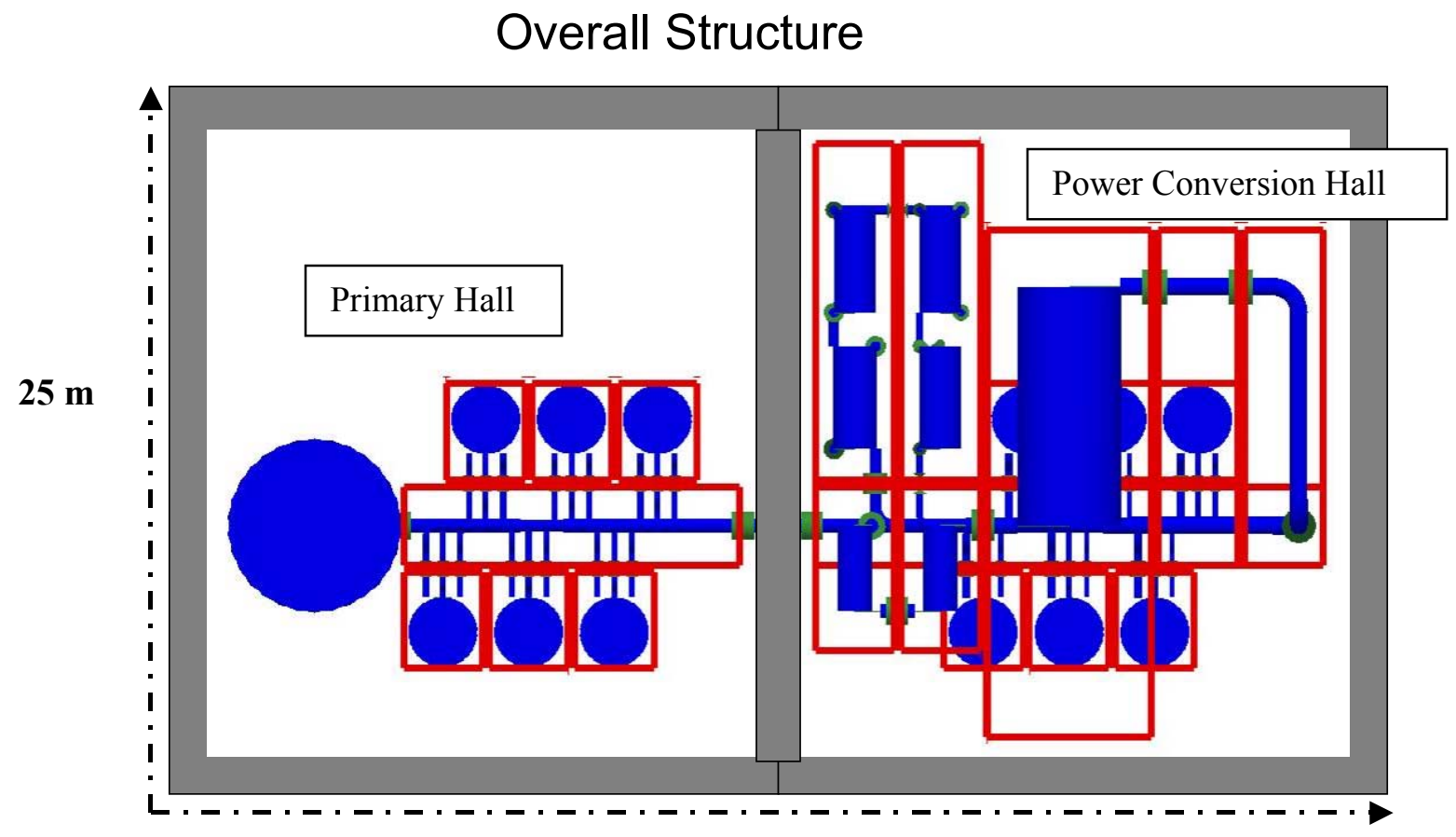

$40 \mathrm{~m}$

Figure 10: Overall Plant Structural Layout

One of the most important critical issues is establishing a central reference line around which to build and ultimately assemble the modules. Even with computer-automated design and construction, these reference lines become important to manage tolerances and assure proper assembly. Having machined parts as line up connections is going to be expensive. Thus, in the space-frame design, it will become important to how much machining and exact positioning of the components in all the interfaces between all the space frames will be required to keep the costs affordable. General Dynamics Corporation has been a leader in integrating engineering and manufacturing in the construction of nuclear submarines. General Dynamics has demonstrated that the degree of labor and cost reduction possible using modularity techniques compared to the old "stick build" approaches. The first submarine using modularity techniques was able to reduce by $16 \%$ the labor costs. The second reduced those labor hours by an additional $23 \%$ with more expected as systems and fabrication approaches become more standardized. This expertise will be required for the implementation of this concept for land based nuclear power plants as well. 


\section{Conclusions}

If new nuclear plants are to be built they must be competitive with alternative sources of energy. One of the biggest disincentives is the high capital cost of new nuclear plants driven largely by the cost of complicated safety systems and the long construction period driven by traditional "stick build" construction practices which are very site labor intensive. A new approach to building nuclear plants is proposed that is based on true modularity in which the size of the plant is driven by the ability to ship by truck (or train) prefabricated modules in space frames for "lego style" assembly. The analysis performed to date and the experience of integrated engineering and manufacturing of nuclear submarines in the United States strongly suggests that these techniques can be applied to land based nuclear plants. This would allow smaller sized reactors to compete on a mass production basis versus traditional economy of scale large nuclear plants on at least three levels: cost of power, faster construction, less financial risk since smaller amounts of money are at risk for smaller periods of time. The small 120 Mwe size of these reactors allows them to be introduced in developing nations and allows developed nations to use these reactors to incrementally add capacity when needed quickly. Should these concepts prove viable, it could revolutionize how nuclear plants are built in the future.

\section{References}

[1] Kadak, Andrew C. "Modular Pebble Bed Reactor Project: University Research Consortium Annual Report", Cambridge, Massachusetts: Massachusetts Institute of Technology, MIT-ANP-PR-075, July, 2000.

[2] Wang, Chunyun, "Design, Analysis and Optimization of the Power Conversion System for the Modular Pebble Bed Reactor System", Ph.D. Thesis, Massachusetts Institute of Technology, Nuclear Engineering Department, August 2003.

[3] Berte, M.V., "Modularity in Design of the MIT Pebble Bed Reactor", Masters Thesis, Massachusetts Institute of Technology, Nuclear Engineering Department, August 2004.

[4] Mynatt, F.R., et al, "Design and Layout Concepts for Compact, Factory Produced, Transportable, Generation IV Reactor Systems," Nuclear Energy Research Initiative Final Report, Grant No. DE-FG07-00SF22168, November 13, 2003. 